\title{
Barriers in health care access faced by children with intellectual disabilities living in rural Uttar Pradesh
}

\section{Jubin Varghese}

Emmanuel Hospital Association

Community Health and Development programme

\section{Nathan Grills}

Nossal Institute for Global Health

University of Melbourne

\section{Kaaren Mathias}

Emmanuel Hospital Association

Umea University in Sweden

$$
\begin{aligned}
& \text { Abstract } \\
& \text { Purpose: People with disability in rural India face multiple barriers accessing } \\
& \text { healthcare; our hypothesis is that children with intellectual disability suffer the same } \\
& \text { but little is known about the barriers faced by them. The objectives of the study were } \\
& \text { to identify the health seeking behaviours of families with children with intellectual } \\
& \text { disabilities and the barriers they faced accessing healthcare. } \\
& \text { Methods: This qualitative study involved interviewing caregivers of children with } \\
& \text { intellectual disability from a pre-existing community development project in the } \\
& \text { Sahadoli Kadim block of rural Uttar Pradesh. Semi-structured interviews were also } \\
& \text { conducted with the local practitioners frequented by these caregivers. }
\end{aligned}
$$


Results: Barriers identified were grouped under cognitive, structural and financial barriers which were found to be consistent with the Health Care Access Barrier Model (Carrillo, et al., 2011; WHO, 2011). Cognitive barriers included caregivers being unable to identify the complex health needs of their children. Caregivers lacked appropriate knowledge of intellectual disability, with doctors failing to educate them. Structural and financial barriers encompassed poor availability of healthcare providers and contributed to poor access to specialists. Caregivers had no information about government financial aid and healthcare providers did not refer them to these.

Conclusion: Children with intellectual disabilities are forced to live with a poor quality of life because of cognitive, structural and financial barriers they face in accessing health care. Results are specific to children with intellectual disability in rural Sahadoli Kadim and could be used to inform policies and strategies to reduce disparities in health care access for these children.

Key words: Intellectual disability, children, access, barriers, health care, rural India

\section{Introduction}

Access to health care is vital for all. For people with disabilities who may have complex secondary medical conditions, this is even truer. According to the World disability report, people with disabilities make up $15 \%$ of the population (WHO, 2011), making them the largest minority group (United Nations, 2006). Despite this, "people with disabilities experience poorer levels of health than the general population. They are often described as having a narrower or thinner margin of health" (WHO, 2011, p. 57). A common assumption is that people with disabilities require only rehabilitation services. This ignores their general health needs and leaves few safety nets to help them deal with repercussions of ill health and hospitalizations. This has been observed by others who note that persons with disabilities often ultimately require more expensive tertiary care as they did not receive adequate preventive care. Others risk developing secondary conditions that may further limit their functioning, quality of life, and life expectancy (Johnson, 2003; Ormel, 1996). 
The situation faced by people with intellectual disabilities is grimmer. Although they make up $2 \%$ of the population in low and middle income countries (Maulik, 2011), people with intellectual disabilities are poorly represented at all forums. Individuals with intellectual disabilities are four times more likely to die of preventable causes than the general population (Horwitz, 2000). Although they experience a number of health problems through their life (Lehmann et al., 2013), they are still less likely to access general health care as compared to the general population and other vulnerable groups (Alborz, McNally, \& Glendinning, 2005; Horwitz, 2000). The U.S. Surgeon General's Report on Health Disparities and Mental Retardation (2001) states that people with intellectual disabilities of all ages experience poorer health outcomes and have more difficulty accessing health care. They are seven times less likely to receive emotional support than people with other disabilities and combined with poorer social networks, they are less likely to be able to use these resources to get well and experience a good quality of life (Havercamp, 2004; Ormel, 1996).

The World Disability Report (WHO, 2011) ranked the identification of barriers in mainstream health care, and strategies for overcoming barriers, as one of the top research priorities. Yet, there is not enough information on children with disabilities and their families accessing health care. This is despite the relatively higher prevalence of intellectual disability compared to other types of childhood disabilities, for example as found in American and European studies (WHO, 2010).

If the paucity of information about children with intellectual disabilities accessing general health care is true for European countries as stated by the WHO document (WHO, 2010), it is also especially true for the children in India. A study done in Gujarat, India found that many village health workers did not even know that mental illness and retardation were disabilities (Morris, 2004).

It is in this context that this study is undertaken. This study aims to identify the specific barriers faced by families with children with intellectual disabilities who access health care in rural communities of Uttar Pradesh (UP), a state in the north of India. These findings could inform policies that promote inclusion of children with intellectual disabilities in mainstream health. 


\section{Method}

A semi-structured qualitative research survey was conducted in the villages in the Sahadoli Kadim block, Saharanpur district, UP through home visits to children with intellectual disabilities. The sample represented a convenience sample as a community health and development project of Emmanuel Hospital Association (EHA) was already functioning in this region. The results of the study were to be used to inform the work being done by the project. EHA is a group of 21 hospitals and 30 community development projects working in the rural areas of North, North-East and Central India. EHA has been involved in seeking to provide inclusive health care through these hospitals and projects.

For the purpose of this study, intellectual disability is used as a general term to talk about people with "mental retardation," "developmental disabilities" (with emphasis on intellectual disabilities), and "learning disabilities". Access was defined along the definition provided by Alborz including the concept of both "physical access to services" as well as "gained access" when services have been successfully used i.e. services responsive to the needs of those who seek them" (Alborz, 2005, p. 174).

In the study, we interviewed the caregivers of children (0-18 years) with intellectual disabilities. Children with intellectual disabilities were identified by the village workers of the EHA community development project. The village workers underwent one day's training on identifying children with intellectual disability. After they had screened the children, the interviewer did a preliminary assessment of the children. The caregivers of these children were interviewed with open-ended questions covering various topics like demographic details, condition of the child, details of minor and serious illnesses their child has had along with preferred places of treatment and reasons for their choices and their perception of health care providers. Snowball sampling was used till data saturation was reached.

A total of thirteen caregivers were approached and ten of them agreed to be interviewed. Four caregivers had boys with disabilities and six had girls with disabilities. Four caregivers were Hindus and six were Muslims. Two Focus Group Discussions (FGDs) were also conducted with families. The interview with the caregivers focussed on their understanding of the health needs of their children and their perception of the organisation of health care. The study explored the availability of services that caregivers found acceptable, and what was required to meet various 
needs given people's differing circumstances. This was done by adopting the "Four As" enquiry (Gulliford et al., 2002; Reichard, 2004), wherein caregivers were asked about the availability, accessibility, affordability and acceptability of health care for their children.

Interviews were also conducted with five health care providers who the research participants visited for healthcare. This interview schedule covered demographic details, their knowledge about intellectual disability, attitudes towards these children and practices when treating children with intellectual disabilities.

Data was collected by the principal investigator through individual interviews. The interviews were recorded by hand with the help of a scribe, and were coded and analysed for relevant and recurring themes. The results were then summarised (below) according to major themes that emerged.

Data was collected and stored in such a way as to preserve the confidentiality of participants. Oral consent was obtained from all the subjects who were interviewed using an approved consent form. Ethics approval was obtained from EHA's Ethics Institutional Review Board.

\section{Results}

Results of the study have been grouped into two categories: identification of health need and the organisation of health care. This was done on the basis of the framework suggested by Alborz to study the health outcomes of people living with intellectual disabilities (Alborz, 2005).

\section{Identification of health need}

Critical to health seeking behaviour is the family's understanding of illness. All caregivers in the study reported that they did not really know what the 'problem' of their child was. All of them said that the health care providers they had taken their children to had been unable to explain the condition of their children to them. Most caregivers described their children as having 'mota dimag' (thick brain) or just used terms like 'gungi' (dumb), 'jhala' (mad) etc. to describe their children.

Caregivers showed diverse understanding of the causes of disability. The most frequent response was that the disability was the child's 'kismet' (fate) and nothing could be done about it. A caregiver described it as "kya karen ji...bus time- 
pass karna hai", meaning since there was nothing that can be done, one can only mark time. Another caregiver said, "What can I do when Allah has made her like this...gungi (dumb)?"

Caregivers were slow to seek help for other medical complaints experienced by the children, for example two children who suffered from seizures were left untreated. Some of the older children had associated medical conditions like dental problems, and psychiatric difficulties, (which in some instances, the caregivers described or which the interviewer was able to observe) but none of them were receiving treatment for any of these conditions. Due to inadequate knowledge about the condition of their child and the understanding that there is nothing one can do (kismet), caregivers usually only sought medical treatment for common childhood ailments like fever, diarrhoea, vomiting etc.

\section{Organisation of health care}

As mentioned under "Methodology", the "Four A" enquiry (Gulliford et al., 2002; Reichard, 2004) was used to assess caregiver's perception of organisation of health care.

a) Availability:

- Presence of providers: Each village that was visited had at least three local doctors known as Registered Medical Practitioners (RMPs) and all caregivers went to them as the first point of treatment. These RMPs referred them to 'higher centres' but only two of the caregivers interviewed had gone to a 'bade doctor' (specialist). One caregiver mentioned that the specialists were so far away that going to them would mean the loss of one day's wages. About half of the caregivers said that they had tried the 'desi' medicines (local medicines) given by the local 'hakim' (traditional healer), hoping that the local medicines would help.

- Transportation difficulties: The closest "higher centre" for people from these villages is about 45 kilometres away, which is a two hour drive due to the poor conditions of the roads. Some of the families travel by motorbike or scooter, requiring the father/brother to take time away from work to accompany the mother, who is usually the primary 
caregiver. One of the caregivers described plaintively her difficulty in taking her daughter for treatment:

"What would you know about how difficult it is (to go to a doctor)? The bus-wallahs do not stop. If they stop, then they hurry you. I have to climb on and hold on to her (daughter). She does not speak. If we get separated, what will happen? She just stands and stares and can go off anywhere. I have to hold on to the bus, to her and the bus conductor shouts at me for being slow. Every time I take her with me, it is a struggle."

b) Accessibility:

- Accessibility was studied in terms of physical accessibility and access to information. Physical accessibility was raised as an issue by one family where the caregiver had difficulty because of her own agerelated difficulties and not because of the disability of the child. In terms of access to information, the issue raised repeatedly by caregivers was that of inadequate information. All caregivers reported that they did not know what the problem with the child was and what their future would be like. They had been told that over time, "baccha teek ho jayega" (the child will become alright). One of them was told to give the child a particular 'tonic for kum dimag' (less brain) for three years and that he would become well. Two caregivers who took their children to specialists were told that the problem was with the nerves and that the children would need to be reviewed every month for the 'nerve medicines' that they were started on. Another family was told that there was nothing to be done for the child and that the family should just take him home and do 'seva-pani' (look after him) as it was the child's 'kismet'. Most caregivers had given up seeking health care in the absence of any 'cure' for their children.

c) Affordability:

- The majority of families mentioned cost as another barrier. 
“... we are a poor family. We have only so much money between yesterday and today... We have to give food and clothes tomorrow as well... For us each child is precious. But to treat this child, we cannot allow the others to starve... Sometimes when there is no choice, we do not look at expenses. We have had to sell whatever wheat we have to pay various doctors."

- Half of the families interviewed talked about having sold either wheat or land or businesses in order to look for treatment for their children.

One caregiver said:

"How much can we spend on treatment? Five years is a long time to give medicines. I have already sold my shop and even after two years, I still do not have enough money to restart the shop. I am forced to go for labour work now."

d) Acceptability:

- All caregivers reported dissatisfaction with treatment, primarily because their children did not get better. Some of them were promised results within three to four months but the medicines were ineffective. One of the caregivers said:

“We don't mind selling land. We would sell some more only if someone would help our child... if someone would tell us what is wrong with the child, the 'bichara' (the poor thing)".

- At the same time, all caregivers reported that the local doctors were kind and helpful and were willing to treat common diseases. If there was any particular issue arising due to the disability, they generally referred to a 'bade doctor' (specialist). One caregiver praised the support they received from the nursing staff when they had been referred to a higher centre. In contrast, another caregiver spoke about the 'bad attitude' of a tertiary care centre they had approached. They felt that the hospital staff were impatient with their child, complaining that the child was uncooperative and even scolding the child for not 
being willing to get a test done. A caregiver with an 18 year old daughter raised another issue about safety at hospitals and clinics for children with intellectual disabilities:

“Usually I don't take her with me, even to doctors. I leave her at home and just explain the difficulties. I have taken her out a couple of times but what is the use. If she spits, vomits, the others dislike it. Why trouble someone else? ... I do not let her go outside, even to the doctor's. Who knows how someone will treat her? It is safe at home. If something happens to her, what will she hear? What will she say? Who knows what she understands?"

In order to get a better perspective of the organisational determinants of health, interviews were also conducted with Registered Medical Practitioners (RMPs). It was found that nearly all the doctors said that they simply treated the common diseases these children might develop like fever, vomiting, diarrhoea etc. Only one doctor said that he was 'a nerve expert' and claimed to have a high success rate in healing those with hemiplegia. He said that he had just launched a new treatment for 'all those with nerve problems'. The person only had to take the course for six months and they would get completely cured.

None of the RMPs believed that there was a need for training on intellectual disability. The doctor who claimed to treat nerve disorders declined training because he felt he had the required expertise. One of the others said:

"...like you try to understand the psychology of a neonate, you must understand the psychology of these children. Like for example, a 4 month old or a 6 month old baby cannot tell you my stomach hurts or my head hurts and we still treat them. We should treat these children in the same way".

The other doctors said that they did not treat anything that is not 'curable' and they simply refer them and therefore need no training. 


\section{Discussion}

This study usefully delineated, that in India, the lack of utilisation of healthcare by those with intellectual disability was a result of poor individual/family understanding of the condition, as well as social factors and system barriers. The main barriers that our study identified were financial, exacerbated by a lack of information about health insurance schemes; structural, including a lack of systematic referral; and thirdly cognitive, particularly a lack of education of both caregivers and health providers regarding intellectual disability, leading to a lack of a preventive care focus. All the barriers interacted with one another in detrimental ways to increase the disparity in access to health care.

This understanding of barriers is parallel to the approach of the Health Care Access Barrier (HCAB) model (Carrillo et al., 2011). Demonstrated in Figure 1, the HCAB model looks at three major barriers that have a causal relationship with poor health outcomes. The three categories of health care access barriers are financial, which includes the cost of treatment, structural, which includes the organisational barriers and cognitive barriers, which include inadequate information, prejudices, communication distance etc. These barriers often reinforce each other, thus, leading to adverse health outcomes.

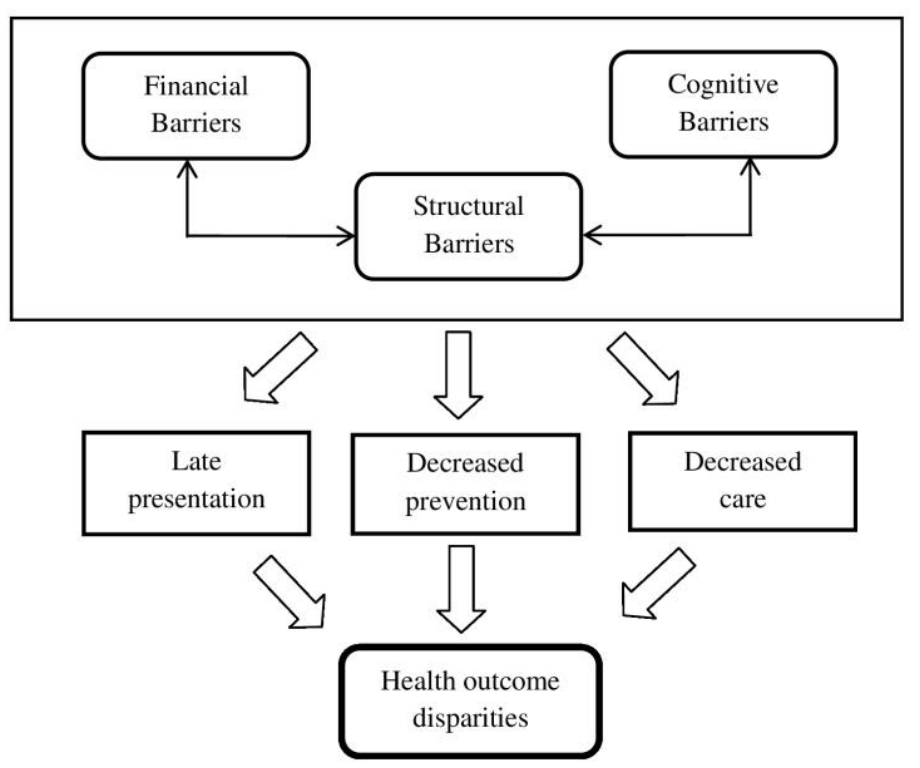

Figure 1. The Health Care Access Barriers (HCAB) model suggested by Carrillo et al. ( 2011). 


\section{Financial barriers}

The stories of families selling land, businesses etc. support the disability-poverty cycle and show how disability succeeds in pushing the family further into poverty. This is in line with previous studies that show that the out-of-pocket expenditure of families with a person with disability is higher than a family with no disability (WHO, 2011) No families were aware of health insurance schemes provided by the National Trust of India (cognitive barriers). The process of being registered for insurance can be a tedious process especially if there are no empanelled hospitals nearby (structural barriers). We therefore see the interaction between barriers leading to financial burden related to accessing health care for families.

\section{Structural barriers}

These refer to barriers in availability and accessibility of services. Studies done show that high transport costs are a significant barrier to mobility - especially as people with disabilities have to spend more on travel as compared to their non-disabled peers (Venter et al., 2002). The situation worsens in rural settings with almost nonexistent roads, inaccessible transport and poor family resources. A study done in the Uttar Pradesh and Tamil Nadu states of India showed that the three main reasons discouraging people with disabilities from using health services were cost (70.5\%), lack of services in the area (52.3\%), and transportation $(20.5 \%)$ (WorldBank, 2007).

Not surprisingly, in the present study, caregivers reported to 'settling for local doctors' because of the absence of 'bade doctors' (specialists) close by. Long distances meant that caregivers had to deal with inaccessible transport and the negative attitudes of drivers and conductors. Treatment becomes even less affordable when transport costs are factored in. There are very few medical insurance schemes that cover transportation costs.

There are no structured systems of referrals or follow up and therefore, almost none of the children in the study are on regular follow up. Caregivers 'pick and choose' their doctors depending on suggestions or testimonies of other people in the community. 


\section{Cognitive barriers}

Lack of understanding about the disability leads to parents shopping around for treatment that moves them into debt, forces them to sell assets and brings them to a place where they become resistant to the idea of seeking any treatment for their children. Cognitive barriers cause children with intellectual disabilities to live with undetected and untreated secondary medical conditions, thus drastically reducing their quality of life.

Lack of adequate knowledge about their child's disability is magnified by cognitive barriers among the health care providers. The findings show that the caregivers receive inadequate information from their health care providers. Ideally, these healthcare providers should refer the caregivers to national health schemes that they are eligible for, but this rarely happens. As seen in the data collected, some health care providers encourage repeated visits by refusing to demystify the condition of the child. In other cases, doctors themselves have little or no information about intellectual disabilities. It was surprising, however, that the local doctors did not want any further training which is unlike the findings of other literature. This may relate to the fact that caregivers tended to only approach local doctors for treatment of the child's common diseases, and the local doctors did not feel they needed to treat or understand the intellectual disability and its associations. Compounding this are negative stereotypes towards people with intellectual disabilities and lower expectations, also a result common in other studies (Lehmann et al., 2013).

The above factors mean that disability and the associated complications remain poorly characterised and undertreated. This is consistent with findings by Horwitz (2000) where these children fall between the cracks with the local doctors refusing treatment for anything other than common diseases and the specialist doctors being too far away or far too expensive.

\section{Recommendations}

This study supports empowerment of individual families of children with disability to help improve their understanding of the condition and their ability to overcome barriers. This includes providing correct information in an accessible format to allow these families to make appropriate decisions. 
Community involvement can also play an import role here. Families affected by disability should be facilitated to be involved in established self-help groups and income generation programs happening in the villages.

These families also need to be assisted in taking advantage of Government poverty reduction schemes and current pension and support schemes. However, it would seem that additional Government safety nets are required for families when faced with medical expenses for their children.

Any system that seeks to improve care for these children needs to address structural barriers by, for example, providing subsidised transport to access care and adequate staffing of these facilities. Health staff themselves need to be well trained in disability in order to limit stigma, support appropriate diagnose and promote collaborative management.

\section{Limitations of the study}

The study only explored knowledge, attitudes and practices of the local registered medical practitioners and the specialists mentioned in interviews could not be interviewed because their clinics/centres were far away.

The small study size and limited geographical setting limits our ability to generalise these findings to other settings. Additionally, this study did not include families of children with mild intellectual disabilities and so their views are not represented.

The results do provide useful data to inform future research around access to healthcare for those children with intellectual disability. The findings may be limited in informing regional/national policy; however they will assist these groups in advocating for entitlements under already established policies.

\section{Conclusion}

This study demonstrates that children with intellectual disabilities live with poor quality of life because of barriers they face in accessing health care. Their health needs remain undetected and untreated because of lack of knowledge among caregivers, inadequate and often inaccurate information provided to the caregivers by the health care providers (cognitive barriers), costs associated with treatment (financial barriers) and unavailability and inaccessibility of services (structural 
barriers). The interaction between the barriers further deepens the impact of disability for the families. Making information available for caregivers, facilitating their organisation into support and advocacy groups and empowering them to obtain government entitlements are steps forward to ensure that children with intellectual disabilities are able to access their right to quality healthcare and experience good health.

\section{Declaration of Interest}

The authors report no declarations of interest.

\section{References}

Alborz, A., McNally, R., \& Glendinning, C. (2005). Access to health care for people with learning disabilities in the UK: mapping the issues and reviewing the evidence. Journal of Health Services Research and Policy, 10, 173-182.

Carrillo, J. E., Carrillo, V. A., Perez, H. R., Salas-Lopez, D., Natale-Pereira, A., \& Byron, A. T. (2011). Defining and targeting health care access barriers. Journal of Health Care for the Poor and Underserved 22(2), 562-575.

Gulliford, M., Figueroa-Munoz, J., Morgan, M., Hughes, D., Gibson, B., \& Beech, R. H. (2002). What does 'access to health care' mean? Journal of Health Services Research \& Policy, 7(3), 186-188.

Havercamp, S. M., Scandlin, D., \& Roth, M. (2004). Health disparities among adults with developmental disabilities, adults with other disabilities, and adults not reporting disability in North Carolina. Public Health Reports, 119(4), 418-426.

Horwitz, S. M., Kerker, B. D., Owens, P. L., \& Zigler, E. (2000). The health status and needs of individuals with mental retardation. Washington, D.C., Special Olympics, Inc.: Yale University.

Johnson, J. L., \& Woll, J. (2003). A national disgrace: Health disparities encountered by persons with disabilities. Disability Studies Quarterly, 23(1), 61-74.

Lehmann, B. A., Bos, A. E., Rijken, M., Cardol, M., Peters, G. J. Y., Kok, G., \& Curfs, L. G. (2013). Ageing with an intellectual disability: the impact of personal resources on well-being. Journal of Intellectual Disability Research, 57(11), 1068-1078.

Maulik, P. K., Mascarenhas, M. N., Mathers, C. D., Dua, T., \& Saxena, S. (2011). Prevalence of intellectual disability: A meta-analysis of population-based studies. Research in Developmental Disabilities, 32(2), 419-436.

Morris, A., Sharma G., Sonpal, D., Damle, S. A., \& Shrivastava, A. (2004). Understanding disability: Attitude and behaviour change for social inclusion: UNNATI - Organisation for Development Education and Handicap International.

Ormel, J., Lindenberg, S., Steverink, N., \& Verbrugge, L. (1996). Subjective wellbeing and social production functions. Social Indicators Research, 46, 61-90.

Reichard, A., Sacco, T., \& Turnbull III, R. (2004). Access to health care for individuals with developmental disabilities from minority backgrounds. Mental Retardation, 42(6), 459-470. 
United Nations. (2006). United Nations Web Services Section, Department of Public Information. Convention on the Rights for Persons with Disabilities: Some facts about persons with disabilities. Retrieved from http://www.un.org/disabilities/convention/facts.shtml

USPHS. (2001). U.S. Public Health Service. Closing the gap: A national blueprint for improving the health of individuals with mental retardation. Report of the Surgeon General's Conference on Health Disparities and Mental Retardation. Washington, D.C.

Venter, C., Savill, T., Rickert, T., Bogopane, H., Venkatesh, A., Camba, J., Maunder, D. (2002). Enhanced accessibility for people with disabilities living in urban areas. PR/INT/248/02. Cornell University ILR School, Department for International Development (UK) Engineering Knowledge and Research: Project R8016. Retrieved from http://digitalcommons.ilr.cornell.edu/gladnetcollect/257

WHO. (2010). Better health, better lives: children and young people with intellectual disabilities and their families. The case for change. World Health Organisation.

WHO. (2011). World Report on disability Main Report (Malta ed., Vol. 1 of 2): World Health Organization and the World Bank.

World Bank. (2007). People with disabilities in India: from commitments to outcomes: The World Bank, Human Development Unit, South Asia Region.

\section{Biographical notes}

Jubin Varghese is a clinical psychologist based in India. She is Programme manager for Disability for the Emmanuel Hospital Association (www.eha-health.org) which is the largest non-profit health care provider in North India. She researches particularly in the area of disability and access to care, as well as mainstreaming disability in the low -resource context, focussing on North India. Jubin is also Deputy Director for the Community Health and Development programme.

Dr Nathan Grills is a Public Health Physician with the Nossal Institute for Global health at the University of Melbourne. He works largely on disability in the Indian context. He also helps facilitate the CHGN Uttarakhand Cluster of 50 community health programs which have a large disability focus (www.chgnukc.org). Academically he researches disability measurement with the Public Health foundation of India and the CHGN Uttarakhand Cluster and the University of Melbourne. Programmatically he helped establish Samvedna CBR program in North India (Emmanuel Hospital Association program. In the past Nathan has extensively researched NGOs in India and completed his MPH and DPhil at the Oxford 
University under a Rhodes Scholarship. He has also worked in Africa, Fiji, East Timor, PNG, Bangladesh and Nepal.

Kaaren Mathias is a New Zealand trained public health physician who has been working in India since 2006. She is Programme manager for mental health for the Emmanuel Hospital Association and based in Uttarakhand. She is currently completing a PhD with the Centre for Global Health and Epidemiology at Umea University in Sweden, focussing on building community mental health competence in North India. Her research interests include a focus on promoting inclusion and access to care for people with both intellectual and psycho-social disabilities. 